\title{
On the Costs and Benefits of Anti-Inflation Policies
}

\author{
LAURENCE H, MEYER and ROBERT H. RASCHE
}

\begin{abstract}
4. prominent policy issue of the 1970s and one that seems certain to dominate the early 1980 s is the appropriate response to a prevailing high rate of inflation. The view that there is a long-run trade-off between inflation and unemployment, widely accepted at the end of the sixties, is now held by only a small minority of economists. It is still widely believed, however, that there is a short-run trade-off between inflation and unemployment, which implies that restrictive macroeconomic policies designed to reduce inflation would cause a temporary rise in the unemployment rate. Therefore, both the time pattern of the response of inflation and unemployment to demand management policies and the relative cost of inflation and unemployment remain dominant issues in the design of macroeconomie policy.
\end{abstract}

There is relatively little consensus on either the costs or benefits of reducing inflation. Both income-expenditure and monetarist macroeconometric models indicate that a deceleration in monetary growth would gradually eradicate inflation but at a sizable cost in terms of foregone output. In contrast, recent theoretical anal$y$ sis based on "rational expectations" suggests that the cost of reducing inflation could be small. Moreover, the literature contains still less information on the cost of inflation, which makes it difficult to obtain a careful balancing of the costs and benefits of policies intended to reduce or eliminate inflation.

This paper develops three views of the dynamics of inflation and unemployment; the expectations-augmented Phillips Curve model, a monetarist model of the relation of monetary change to both inflation and unemployment, and a rational expectations model. Based on each of these models, estimates of the cost of reducing inflation are presented. Finally, the size of the permanent per period gains associated with eradicating inflation that would justify incurring these temporary costs are estimated using both the Phillips Curve and monetarist models.

\section{THREE VIEWS ON THE PRLATION BETWETN TNELATION AND UNEMPEOMENT}

The Phillips Curve approach, as employed in virtually all large-scale, income-expenditure macroeconometric models, relates inflation to the unemployment rate and inflation expectations and almost uniformly specifies inflation expectations as dependent exclusively on past actual inflation rates. Some monetarists, however, prefer to relate both inflation and unemployment directly to monetary change and reject the regularity between inflation and unemployment embodied in the Phillips Curve. A third view accepts the Phillips Curve but introduces an altemative hypothesis about expectations formation. This rational expectations approach yields conclusions quite different from the first two approaches.

\section{The Phillips Curve}

The Phillips Curve relates the rate of change in nominal wages to both the unemployment rate and the rate at which wages and/or prices are expected to rise. This is usually combined with a mark-up model of price determination in which prices are related to wages. A combination of the two hypotheses yields a relation between inflation $(p)$, unemployment $(u)$, and expected inflation $\left(\mathrm{p}^{\mathrm{e}}\right)$ :

(1) $\mathrm{p}=\alpha+\beta u+p^{e}, \quad \beta<0$.

There are two basic sources of inflation identified in equation 1: a demand factor and an expectations factor. The unemployment rate is a proxy for the 
balance between supply and demand in the labor market. The lower the unemployment rate, the greater the demand relative to the supply of labor. When there is excess demand for labor, wages are bid up at a rate proportional to the degree of excess demand. Workers and firms bargain directly about nominal wages, but labor supply and demand depend on the real wage rate. ${ }^{1}$ Hence, the bargaining for nominal wage increases over any period will also depend on the rate of inflation expected over that period.

According to the Phillips Curve perspective, demand management policies affect inflation by affecting aggregate demand and, hence, unemployment. While in principle economic policy could affect inflation expectations directly, the specification of the Phillips Curve in macroeconometric models generally assumes that inflation expectations are formed adaptively, that is, they depend exclusively on past inflation rates. A simple form for such an equation is:

(1') $\mathrm{p}_{\mathrm{e}}=\alpha+\beta \mathrm{u}_{\mathrm{t}}+\mathrm{p}_{t-1}$,

where $p_{t}$ is the rate of inflation over some period, $u_{t}$ is the average unemployment rate over the period, and $p_{t-1}$ is last period's inflation rate and, hence, this period's expected rate.

The role of lagged inflation in the Phillips Curve may also reflect the direct influence of past wage and price changes on current inflation due to catch-up effects and long-term contracts. Contracts that fix wages over some period, typically from one to three years, permit current wage settlements to influence wages and prices over the duration of the contract, building an element of persistence or inertia into the inflation process. ${ }^{2}$

In the specification given by equation $1^{\prime}$, there exists a critical unemployment rate consistent with either price stability or constant inflation. ${ }^{3}$ Setting $\mathrm{p}_{\mathrm{t}}=\mathrm{p}_{\mathrm{t}-\mathrm{1}}$, the critical value of $u$ is $u^{*}=-\alpha / \beta$. This is often referred to as the natural rate of unemployment or the nonaccelerating inflation rate of unemployment

1If escalator clauses were both universal and complete, bargaining would be in terms of real wages. The existence of partial escalator clauses for some workers speeds the response of wage to price change, but doesn't alter the fact tha: nominal wage bargains must directly reflect inflation expectations over the duration of the contract

see John B. Taylor, "Staggered Wage Setting in a Macro Model" American Economic Review, Papers and Proceedings (May 1979), pp. 108-13, for a model that incorporates both forwark-looking and backward-looking elements in the wage setting decisions.

3The existence of an equilibrium or natural rate of unemployment independent of the rate of inflation depends on the coefficient of inflation expectations in equation 1 or lagged infation in $\mathbf{l}^{\prime}$ being equal to unity.

\section{敖}

\section{Figure 1}

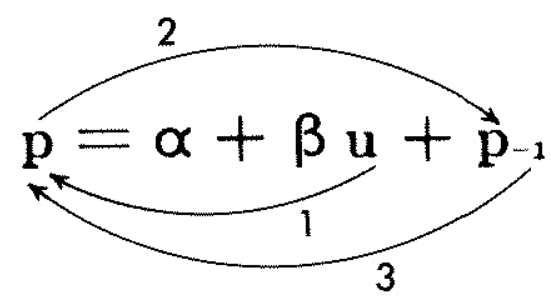

(NAIRU). Anti-inflation policy operates by raising u above $\mathrm{u}^{*}$; as long as $\mathrm{u}$ is greater than $\mathrm{u}^{*}$, inflation decelerates and ultimately is eradicated.

Figure 1 depicts this cycling down process. First, policy reduces aggregate demand. This raises u above $\mathrm{u}^{*}$ and induces a deceleration in inflation (link 1). The decline in the actual inflation rate, in turn, reduces inflation expectations via the $\mathrm{p}_{-1}$ term (link 2), which further reduces actual inflation in the next period (link 3). As long as u remains above $u^{*}$, this cycling down continues. Ultimately, u returns to $\mathbf{u}^{*}$ when inflation has been fully eradicated. Thus, eradicating inflation requires a temporary rise in the unemployment rate during the transition to price stability.

\section{Monetaris Reduced-Fon Fquations}

Stein has developed a "monetarist" framework for assessing the relation between inflation and unemployment. ${ }^{4}$ Stein's basic inflation equation can be expressed as:

(2) $\mathrm{p}_{\mathrm{t}}-\mathrm{p}_{\mathrm{t}-\mathrm{t}}=\mathrm{a}\left(\mathrm{m}_{\mathrm{t}}-\mathrm{p}_{\mathrm{t}-1}\right)$,

where $m_{t}$ is the rate of monetary growth in period $t$. According to this specification, inflation accelerates when monetary growth exceeds the previous period's rate of inflation.

The distinctive feature of the monetarist equation is not that it identifies monetary growth as the key factor driving inflation while the Phillips Curve ig-

\footnotetext{
Terome L. Stein, "Inflation, Employment and Stagflation," Joumal of Monetary Economics (April 1978) pp. 193-228.

Similar approaches have been presented by Carlson and Tatom: Keith M. Carlson, "Inflation, Unemployment, and Money: Comparing the Evidence from Two Simple Models," this Review (September 1978), pp. 2-6; and John A. Tatom, "Does the Stage of the Business Cycle Affect the Inflation Rate?" this Review (September 1978), pp. 7-15.
} 
nores the influence of monetary change on inflation. The Phillips Curve itself is consistent with monetary change as a dominant influence on the inflation rate. However, it is a specification of the structure of the inflation process, that is, how monetary change affects inflation. According to the Phillips Curve interpretation, a decline in monetary growth moderates inflation by temporarily raising unemployment. The monetarist equation, in contrast, directly relates monetary growth to inflation and is essentially a reduced-form equation relating inflation to policy instruments. In contrast to the Phillips Curve, however, equation 2 allows only monetary change to affect inflation. It also appears to make the acceleration of inflation independent of demand conditions in the economy. In fact, however, the unemployment rate itself is also affected by monetary growth in the Stein model. ${ }^{5}$ Hence, in both the Phillips Curve and monetarist frameworks, a decline in monetary growth both increases unemployment and reduces inflation. Both approaches therefore permit us to calculate the temporary rise in unemployment associated with anti-inflation policy. ${ }^{*}$

\section{Equilibrium Models and Rational Expectations}

Recently there has been renewed interest in equilibrium models in which monetary change results in an immediate proportional change in the price level. ${ }^{7}$ A useful point of departure here is a simple inflation reduced-form equation in which the inflation rate equals the rate of monetary growth:

(3) $\mathrm{p}=\mathrm{m}$.

This differs from traditional monetarist models in allowing the full effect of monetary change on prices to occur immediately. The Phillips Curve then determines the unemployment rate. It is convenient to rearrange equation 1 as:

(4) $u=u^{*}+1 / \beta\left(p-p^{*}\right)$,

which demonstrates that unemployment deviates from

SStein's unemployment rate equation is presented later when his model is used to derive the response of inflation and unemployment to monetary change.

Note, however, that inflation is expected to fall as long as $u>u^{*}$ according to the Phillips Curve; in the monetarist model, on the other hand, an acceleration in monetary growth induces an acceleration in inflation even if the unemployment rate initially is above its critical $u^{*}$ level. Despite this difference, the two approaches yield similar implications for the time path of unemployment and inflation in response to a deceleration in monetary growth.

7For example, see Thomas J. Sargent and Neil Wallace, "Rational Expectations and the Theory of Economic Policy," Journal of Monetary Economics (April 1976), pp. 169-85. The model developed below is simiar to the one developed by Sargent and Wallace. its natural rate only in response to unanticipated inflation.

Monetary change determines the actual inflation rate (via equation 3 ). Inflation expectations, according to the rational expectations view, are formed on the basis of the relevant economic theory - in this case on the relevant model of the inflation process and are conditional on all relevant available information. Taking the expected value of inflation from equation 3 ,

(5) $\mathrm{p}^{\mathrm{e}}=\mathbf{E}(\mathrm{p})=\mathrm{E}(\mathrm{m})$,

where $E(m)$ is the expected rate of monetary growth conditional on information available prior to the period over which the expectations apply, equation 4 can be rewritten as:

$\left(4^{\prime}\right) \mathrm{u}=\mathrm{u}^{\alpha}+1 / \beta(\mathrm{m}-\mathrm{E}(\mathrm{m}))$.

This implies that unemployment is affected only by unanticipated monetary change.

In the previous two models, a deceleration in monetary growth reduces the growth in nominal demand, but inflation unwinds gradually; the decline in the growth of nominal demand, therefore, initially falls heavily on real demand and, hence, initially reduces output and employment. In this model, in contrast, monetary deceleration increases unemployment only if the monetary deceleration is unexpected. If it is announced in advance and reflected in expectations, a rapid deceleration of inflation results with no temporary rise in unemployment and, hence, no cumulative output loss.

However, a question remains: How rapidly would the expected rate of monetary growth decelerate even if the Fed announced a policy of phased deceleration? Barro's attempt to implement this model empirically holds that economic agents base their expectations of monetary growth in part on past monetary growth. ${ }^{8}$ In a sense, such a specification substitutes past actual rates of monetary growth for past actual inflation rates and, therefore, does not entirely remove the inflation inertia embedded in the traditional Phillips Curve. Meltzer also has recently emphasized the gradual process whereby expectations of future monetary growth respond to current observations of monetary policy actions. The overall framework,

sRobert J. Barro, "Unanticipated Money Growth and Unem" ployment in the United States," American Economic Review (March 1977), pp. 101-15.

MAllan H. Meltzer "The Case for Gradualism in Policies to Reduce Inflation," Stabitization Policies: Lessons from the 1970s and Implications for the 1980s (St. Louis: Washington University, Center for the Study of American Business), forthcoming. 
Chart 1

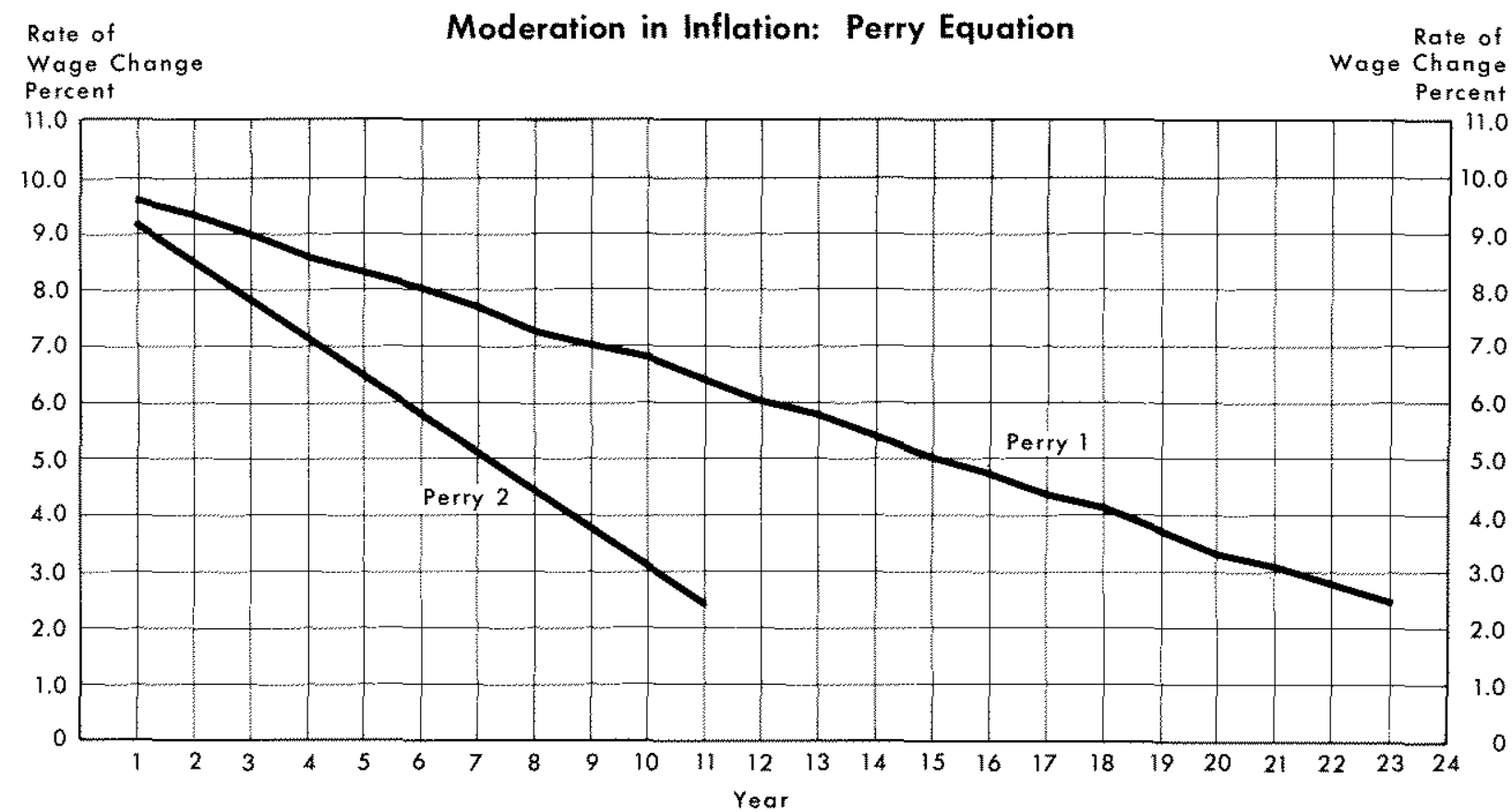

however, suggests that the Fed can minimize the cumulative output loss by carrying out its anti-inflation policy in a manner that makes it easy for the public to discern its intent; this means developing a reputation for meeting its monetary aggregate targets and reducing the volatility of monetary growth so it is easy to recognize changes in the target rate when they occur.

\section{THE RESPONSE OF WNILATON AND OUTPUT TO ANTINWLATION POLCIN}

\section{Resuls Based on Eamated Phllps Curves}

When developing an estimate of the cost of antiinflation policy using a Phillips Curve, anti-inflation "policy" is identified with an increase in the unemployment rate above the critical rate. Underlying the change in the unemployment rate, but implicit in the analysis, are changes in monetary and fiscal policy instruments. As long as the unemployment rate is maintained above the critical rate, inflation will decelerate. Based on the assumed initial inflation rate and on the estimated parameters in the Phillips Curve, it is simple to calculate how long it will take to eradicate inflation.

The final step in estimating the cost of an anti-inflation policy is to convert the increased unemployment into a measure of the cumulative output loss. This is done via Okun's Law: Each 1 percentage point increase in the unemployment rate reduces real output by 3.2 percent. $^{10}$ Thus, at the 1978 value for potential output, for example, a 1 percentage-point rise in unemployment translates into a 45.6 billion dollar loss in output. The cumulative but undiscounted loss can be found by assuming that potential output will rise at a 3.3 percent rate in line with projections by the CEA. The cumulative loss (L) in this case is:

(6) $L=\sum_{t=0}^{n} \gamma\left(u-u^{*}\right)(1+\rho)^{t}$,

where,

$\gamma=$ the Okun coefficient,

$\mathrm{u}=$ the level of unemployment brought on by policy,

$\mathrm{u}^{\circ}=$ the critical unemployment rate,

$p=$ the rate of growth of potential output, and

$\mathrm{n}=$ the number of years required to eradicate inflation.

${ }^{10}$ Arthur M. Okum, "Potential GNP: Its Measurement and Significance, from Proceedings of the Business and Economics Statistics Section of the American Statistical Association (1962), pp. 98-104. More recent estimates of Okun's Law suggest that the ontput loss might be only 2.5 percent for each 1 percent increase in unemployment. See, for example, the estimates in the St. Louis model in Leonall C. Andersen and Keith M. Carlson, "A Monetarist Model for Economic Stabilization," this Review (April 1970), pp. 7-25, and Tatom's discussion of Okun's Law in "Does the Stage of the Business Cycle?" 


\section{Chart 2}

\section{Cumulative Oułput Loss: Perry Equation}

Oufput loss

Billions of 1972 Dollars

Output Loss

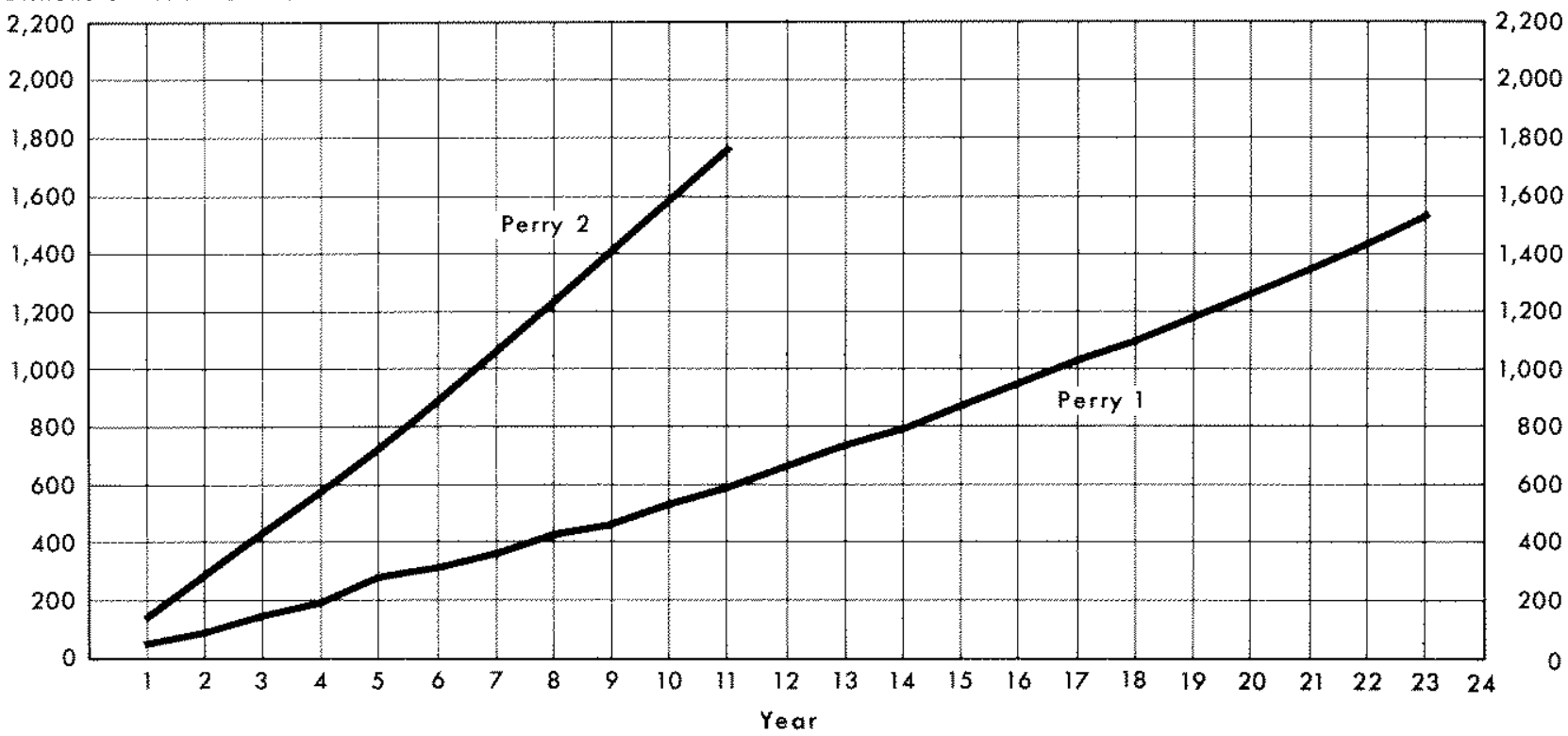

The discounted output loss is simply the product of the initial year's loss and the number of years required to complete the program."

The estimate of the cumulative output loss based on a Phillips Curve equation presented in this section is derived from the results of a study by Perry. ${ }^{12}$ Perry's results are based on a wage change equation, using the inverse of his weighted unemployment rate and lagged wage change, estimated using annual observations over the 1954-77 period:

(7) $\Delta \ln W=\underset{(-2.2)}{-1.88}+\frac{7.44}{(3.5)}(1 / \mathrm{UW})+\underset{(4.6)}{0.79} \Delta \ln \mathrm{W}_{-1}+$

$0.21 \Delta \mathrm{In} \mathrm{W}_{-2}+1.07 \mathrm{DNIX} \quad \mathrm{SE}=0.70$,

(1.1) (2.9)

where $W$ is adjusted hourly earnings in the private nonfarm sector and DNIX is a dummy for the controls equal to -1 in 1972 and 1973 and +1 in 1974 and 1975 . His preferred equation yielded a NAIRU of $4.0 \mathrm{in}$ terms of his weighted unemployment rate (which corresponds to about 5.5 percent in the official unemployment rate in 1977). Hence, any un-

11This is the same as discounting future years' losses by a 3.3 percent real interest rate.

12George L. Perry, "Slowing the Wage Price Spiral: The Macroeconomic View," Brookings Papers on Economic Activity (2: 1978), pp. 259-9l. Similar estimates have been presented by okun and Gramlich. Arthur M. Okun, "Efficient Disinflationary Policies," American Economic Review, Papers and Proceedings (May 1978), pp. 348-52; and Edward M. Gramlich, "Macro Policy Responses to Price Shocks," Brookings Papers on Economic Activity (1: 1979), pp, 125-66. employment rate above 5.5 percent, if maintained long enough, would eradicate inflation.

In the following simulations, inflation is assumed initially to be 7.5 percent, and the economy is assumed initially to be at the critical unemployment rate (NAIRU). The time it would take to eliminate inflation if unemployment were raised by either 1 or 3 percentage points is then calculated.

The response of inflation to a rise in the unemployment rate and the accompanying cumulative output loss are depicted in charts 1 and 2: Perry 1 corresponds to a 1 percentage point rise in the unemployment rate and Perry 2 to a 3 percentage-point rise. Beginning with $\Delta \ln W$ (approximately the percentage change in the wage rate) equal to 10 percent, the unemployment rate is raised above NAIRU and held there until the rate of wage change declines to 2.5 percent, the rate presumed consistent with the trend growth in labor productivity and, hence, with price stability. When unemployment is raised 1 percentage point, the rate of change in the wage rate falls from 10 percent to 9.6 percent in the first year and declines about 0.3 percentage points per year thereafter, taking 23 years to reach the 2.5 percent rate consistent with zero price inflation. The undiscounted cumulative output loss is $\$ 1.5$ trillion, and the discounted cumulative output loss is $\$ 1$ trillion. 


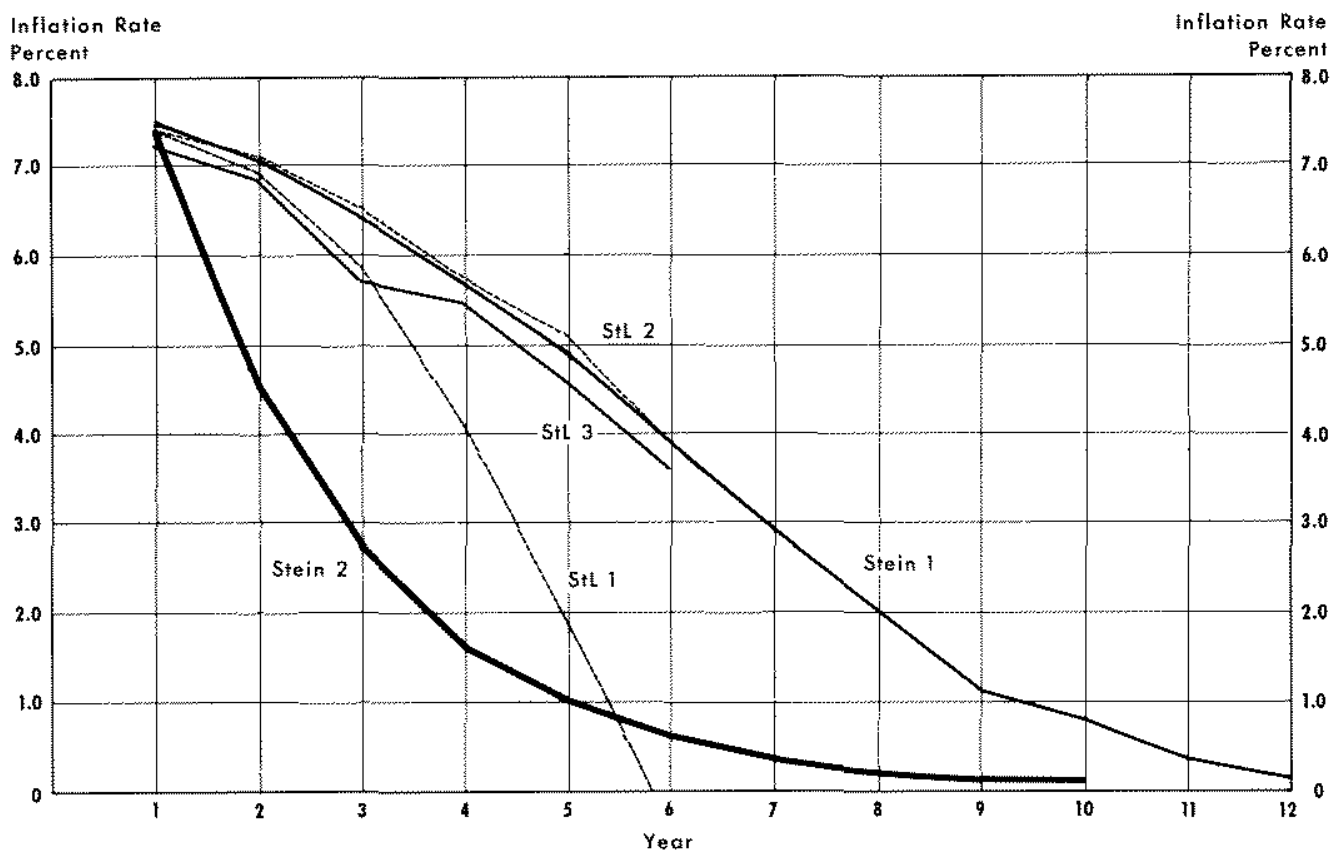

If unemployment is raised by 3 percentage points, inflation is eliminated after 11 years. The cumulative output loss, however, is greater in this case: $\$ 1.8$ trillion in the undiscounted case and $\$ 1.5$ trillion in the discounted case. ${ }^{13}$

\section{Results Based on a Monetarist Model}

According to Stein's monetarist model, monetary change affects both inflation and unemployment. Stein's two-equation model is:

(8) $\Delta \mathrm{u}_{\mathrm{t}}=3.0-0.6 \mathrm{u}_{\mathrm{t}-1}+0.4 \mathrm{p}_{\mathrm{t}-1}-0.4 \mathrm{~m}_{\mathrm{t}-1}$

(9) $\Delta \mathrm{p}_{\mathrm{t}}=-0.4 \mathrm{p}_{\mathrm{t}-1}+0.4 \mathrm{~m}_{\mathrm{t}-1 \mathrm{k}}$.

If monetary growth remains constant, inflation converges to the rate of monetary growth, and unemployment converges to a constant rate, equal to 5 percent in Stein's model. Hence, the equilibrium rate of inflation equals the rate of monetary growth, and the critical unemployment rate is 5 percent. If monetary growth declines below the rate of inflation, inflation

13 While most reported Phillips Curves yield high estimates of cumulative output loss in line with Perry's, there are some that imply much lower estimates. For example, see the Phillips Curve presented by Phillip Cagan in "The Reduction of Inflation by Slack Demand," in William Fellner, Project Director, Contemporary Economic Problems in 1978 (Washington, D.C.: American Enterprise Institute for Public Policy Research, 1978), pp. 13-45. The cumulative output loss based on Cagan's equation is only about one quarter of that implied by Perry's equation. decelerates and unemployment temporarily rises above its equilibrium rate.

The simulation used to derive an estimate of the cumulative output loss from Stein's model differs from that used in the Phillips Curve approach. Since inflation and unemployment are both linked directly to monetary change in the monetarist model, the rate of monetary growth can be used as the policy instrument. As" sume that the rates of monetary growth and inflation are both 7.5 percent initially and that the economy is at the equilibrium unemployment rate. Anti-inflation policy is identified with a deceleration in the rate of monetary expansion. Now, consider two scenarios: a phased deceleration of monetary growth by 1 percentage point per year until the rate of monetary growth declines to a rate which, if maintained, would be consistent with price stability (zero in this model) and an immediate deceleration to the rate consistent with long-run price stability. Imposing these alternative paths of monetary change on the model generates the associated implied paths of inflation and unemployment; the rise in unemployment above 5 percent is then translated into a measure of the cumulative output loss.

The effects of each policy on inflation and output loss are depicted in charts 3 and 4; the Stein 1 lines correspond to the gradual deceleration in monetary 


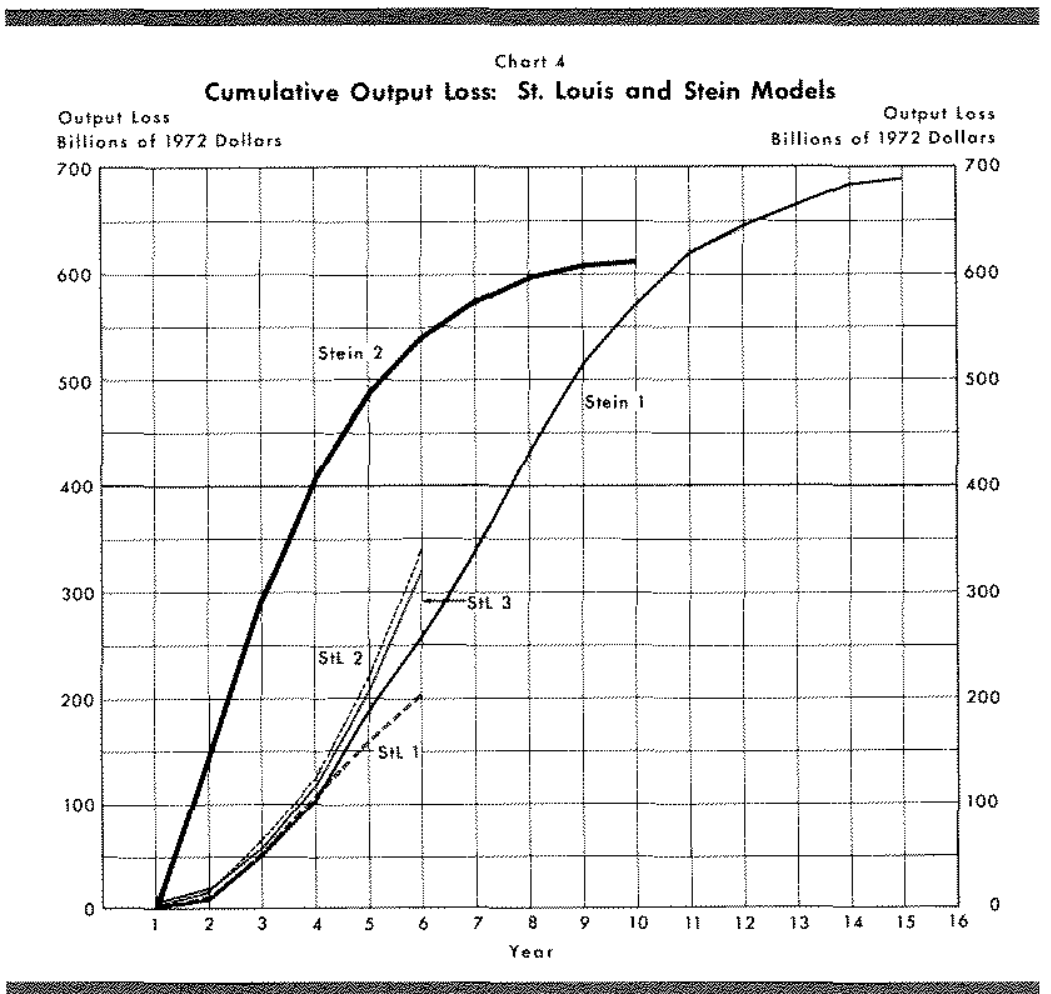

key equations in the St. Louis model are a reduced-form equation for the rate of growth in nominal income based on the Andersen-Jordan equation and an expectations-augmented Phillips Curve. ${ }^{15}$ The rate of monetary change is the principal determinant of the rate of change in nominal income, although the rate of change in high-employment government expenditures also has a small, transitory effect. Thus, a decline in the rate of monetary growth is quickly translated into a decline in the rate of increase in nominal income. The distribution of the latter decline between prices and output depends on the Phillips Curve; the slower the deceleration of inflation as nominal income falls, the greater the impact of monetary change on output and the greater the resulting cumulative output loss of anti-inflation policy.

To begin, a base run in which the rate of monetary growth is held steady at 7.5 percent from III/1968 through IV/1978 was generated. This builds in inflation in-

growth, the Stein 2 lines represent the more aggressive policy. Under the gradual policy, unemployment begins to rise in year 2 , peaks in year 8 at 6.6 percent, and returns to almost 5 percent by year 16 . The inflation rate, on the other hand, begins to decelerate in year 2 , initially at a 0.4 percentage point a year rate, ultimately reaching 1.0 point per year by year 7. The inflation rate is down to 2 percent by year 8 and thereafter declines gradually to about zero by year 16. The undiscounted cumulative output loss is $\$ 687.5$ billion. Interestingly, the more aggressive policy incurs a smaller undiscounted output loss, $\$ 613$ billion.

Note that, qualitatively, the results are similar to those based on the Phillips Curve: Restrictive demand management policy temporarily will raise unemployment as it induces deceleration in the rate of inflation. The size of the cumulative output loss in the Stein model, however, is dramatically lower than that based on Perryss equation.

\section{Results Using the St. Lomb Model}

The St. Louis model is in some sense a compromise between the Phillips Curve and the monetarist reduced-form approaches developed above. ${ }^{14}$ The two

14'The St. Louis model is described in Andersen and Carlson, "A Monetarist Model." ertia and provides the base against which to evaluate the effects of gradual monetary deceleration. Beginning in $1 / 1973$, monetary growth was gradually decelerated by 1 percentage point in the first quarter of each year. The results from this policy run were then compared with those from the base run and the cumulative output loss associated with this policy was derived by comparing the output solution assuming monetary growth remains at 7.5 percent per year with that assuming a phased monetary deceleration. ${ }^{16}$

The first set of simulations was generated using the St. Louis model estimated over the sample period I/1953-IV/1978. The results, labeled StL1, are reported in charts 3 and 4 . The inflation rate begins to decline slowly; indeed, it takes 2 years to reduce it by 1 percentage point. Thereafter, the deceleration speeds up; after $5^{1 / 2}$ years, inflation has declined by 7.5 percentage points. The unemployment rate initially rises slowly, and the maximum increase is only 1.8

15Leonall $C$. Andersen and Jerry L, Jordan, "Monetary ard Fis" cal Actions: A Test of Their Relative Importance in Economic Stabilization," this Review (November 1968), pp. $11-24$

16Because the model produces direct solutions for the response of output to monetary deceleration, the use of Okun's Law is not required. 
percentage points. The undiscounted cumulative output loss is only about $\$ 200$ billion. ${ }^{17}$

The estimate of the cumulative output loss in this case is dramatically lower than for either the Stein model or the Perry equation. However, the small size of the cumulative output loss reflects, in part, the suspiciously large coefficient on the demand slack variable in the model's Phillips Curve - almost three times the size of the same coefficient estimated through II/1971 or I/1975, for example. This rise in the demand slack coefficient is neither readily explained nor mirrored in other estimates of Phillips Curves. Consequently, two additional runs with modified versions of the St. Louis model were made.

First, a simulation of the model estimated through III/1971 in which the coefficient on the demand slack variable is substantially smaller was run. The results are depicted by the StL2 lines in charts 3 and 4 . Inflation decelerates much more gradually; after six years, it has declined by only 4 percentage points. The cumulative output loss, already at $\$ 350$ billion, is escalating rapidly.

In the second modified version of the St. Louis model, the Phillips Curve was replaced with a monetarist reduced form for the inflation rate in which inflation depends on a 20-period distributed lag on the rate of change in the money supply. ${ }^{18}$ The lines labeled StL 3 in charts 3 and 4 present the implications of gradual monetary deceleration on inflation and output in this case. The results are remarkably similar to those generated by the first modified version of the St. Louis model (StL2 lines in charts 3 and 4). The inflation rate declines somewhat more rapidly and the output loss is a bit smaller, but both the time pattem and magnitude of inflation deceleration and output loss are very close.

The StL2 and StL3 simulations were not run long enough to eradicate inflation and, therefore, are not directly comparable with the Phillips Curve and monetarist reduced-form results. Nonetheless, the results

17In the Perry and Stein results, the initial level of potential output was that for 1978 . The $\$ 200$ billion cost estimate for the St. Louis model is based on an initial level of income in 1973. To make the St. Lonis result comparable with the Perry and Stein results, it would be appropriate to multiply it by a factor equal to the ratio of potential output in 1978 to that in 1973 .

18The inflation reduced form was provided by Tatom and is similar to the one he presented in "Does the Stage of the Business Cycle?" In addition to the distributed lag on monetary change, it also includes a four-quarter distributed lag on the differential in the rates of change in producer prices for energy and the price index for the nonfarm business sector as well as two dummies, one for the effects of the freeze and Phase II and one for the subsequent catch-up effect. at the end of six years were qualitatively similar to the Perry and Stein results: Anti-inflation policies impose a sizable cost in the form of lost output during the transition to lower inflation rates. ${ }^{19}$

\section{The Crediblthy Effect and Rational Expectations}

The Phillips Curve-based results reported above related inflation to a distributed lag of past inflation rates, which implies a gradual unwinding of inflation in response to anti-inflation policies. In this specification, inflation expectations are formed exclusively on the basis of past actual inflation. This ignores the possibility that the public will adjust their inflation expectations to both recent policy actions and expectations about future policy. A well-defined, credible anti-inflation policy might induce a more rapid deceleration of inflation expectations than is suggested by the conventional equations. Felner, for example, maintains that ". . . the standard model coefficients ... would change significantly for the better - in the direction of a much more rapid rate of reduction of inflation for any given slack - if a demand management policy ... changed to a credible policy of consistent demand disinflation." 20

But, by how much do standard econometric approaches overestimate inflation inertia and the associated cumulative output loss? Unfortunately, reliable quantitative estimates of the extent to which policymakers can speed the deceleration of inflation by clearly defining their anti-inflation policies and convincing the public that they intend to follow through do not exist. Nevertheless, there is widespread agreement that anti-inflation policies ought to be set out clearly and supported by both the Federal Reserve and the Treasury to maximize credibility.

There are, however, two empirical applications of rational expectations macro models that provide some insight into the predictions of that approach for the response to a phased monetary deceleration. Paul A.

${ }^{19}$ Dewald recently presented simulations of the response of inflation, output, and unemployment to monetary deceleration based on a modified version of the St. Louis model. William G. Dewald, "Fast vs. Gradual Policies for Controlling Inflation," Federal Reserve Bank of Kansas City Economic Rèview (January 1980), pp. 16-25. He estimates the Phillips Curve in the rate of change as opposed to the first difference form used in the St. Lonis model. "This procedure does not yield a coefficient on the demand slack variable as high as in the St. Louis specification. Hence, Dewald also finds that monetary deceleration yields a large cumulative output loss,

${ }^{20}$ William Fellner, "The Credibility Effect and Rational Expectations: Implications of the Gramlich Study," Brookings Papers on Economic Activity (1: 1979), pp. $167-78$. 
Anderson modifies the St. Louis model by respecifying its Phillips Curve to be consistent with rational expectations. ${ }^{21}$ He begins with a Phillips Curve of the following form:

(10) $p=\alpha+\beta \chi+e p^{*}+\varepsilon$,

where $X$ is a measure of demand slack in the economy, and $\varepsilon$ is a random disturbance term with mean zero. Instead of specifying $\mathrm{p}^{*}$ as a distributed lag on past actual inflation rates as in the equation in the St. Louis model, Anderson imposes rational expectations by setting $\mathrm{p}$ equal to the expected value of inflation based on equation 10. Setting $\mathrm{p}^{\mathrm{e}}=\mathrm{E}(\mathrm{p})$, he solves for the expected value of inflation:

(10 $) \mathrm{E}(\mathrm{p})=\frac{\alpha}{1-\mathrm{e}}+\frac{\beta}{1-\mathrm{e}} \mathrm{x}$.

Anderson uses this equation to determine the inflation rate in the St. Louis model, based on the estimates of $\alpha, \beta$, and e from the St. Louis Phillips Curve. In particular he sets $\mathrm{e}=.86$. This procedure, in effect, dramatically raises the response of inflation to changes in demand slack. He muns simulations of the response to an acceleration in the rate of monetary growth. In the original St. Louis version, inflation increases gradually and unemployment declines; in the rational expectations version, inflation increases more rapidly and the effect on tnemployment virtually disappears.

If $\mathrm{e}$ is viewed as the coefficient on expected infla tion, however, it seems inappropriate to employ its value of .86 as estimated in the St. Louis model in the rational expectations version of the St. Louis model because it was estimated originally under the assumption that expectations are formed adaptively. Taking $\mathrm{e}=1$, as seems essential to the rational expectations framework, equation $10^{\prime}$ is no longer a meaningful equation for $p$. Instead, setting $\mathrm{p}^{e}=\mathrm{E}(\mathrm{p})$ and solving for $E(p)$, we obtain:

$\left(10^{\prime \prime}\right) 0=\alpha+\beta x$,

which indicates that there is a unique value of the demand slack variable $\left(\chi^{*}=-\alpha / \beta\right)$, corresponding, of course, to the natural rate of unemployment. Only random disturbances (with zero mean) can cause $X$ to differ from $X$. In this case, the impact of monetary deceleration on the rate of growth of nominal income is transformed immediately and fully into a decline in inflation without any cumulative output loss.

An altemative empirical application of a rational expectations macro model is presented by Barro. ${ }^{22} \mathrm{He}$

\footnotetext{
${ }^{21}$ Paul A. Anderson, "Rational Expectations Forecasts from Nonrational Models," Journal of Monetary Economics (Jannary 1979), pp. 67-80.

22Barro, "Unanticipated Money Growth."
}

relates deviations in unemployment from its natural rate to unanticipated monetary change (as in equation $4^{\prime}$ above) and, in addition, provides a model describing how economic agents form expectations about the rate of monetary growth. On the surface at least, Barro's model seems well suited to provide an estimate of unemployment's response to a policy of phased deceleration in monetary growth. The crucial issue here is how rapidly economic agents learn that the policy rule has in fact changed. They may learn this from an announcement by the Fed. Given some doubt about the Fed's commitment to follow through on any announced deceleration, however, economic agents may insist on learning the new policy rule by observing the new pattern of monetary growth rates. This involves reestimating the policy rule and incorporating new observations each period. Eventually, economic agents will learn that the Fed intends to decelerate monetary growth and then stabilize it at a noninflationary rate, But this learning process may take some time; meanwhile, monetary change will be less than expected and unemployment will exceed the natural rate. Hence, the Barro model also allows for the existence of a cumulative output loss during the transition to price level stability. ${ }^{23}$

The survey above provides the following cost estimates: the extremely large estimate of the cumulative output loss based on Perry's Phillips Curve, the smaller but still sizable loss based on Stein's monetarist model, the evidence from simulations with the St. Louis model which, on balance, also suggest a large output loss, and the rational expectations results as modeled by Anderson, which suggest virtually no output loss if monetary deceleration is perfectly anticipated. Unfortunately, in addition to the uncertainty surrounding the actual cumulative output loss likely to be associated with anti-inflation policy, there is also uncertainty about the benefits to be derived from eradicating inflation.

\section{DALANCING TTE CANS AGANST THE COSTS}

The cumulative output loss is a measure of the costs of anti-inflation policies. To evaluate the desirability of such policies, an assessment of the gains from reducing inflation is required. Unfortunately, the costs of

23 This is an application of the learning mechanism emphasized by Johm B. Taylor, "Monetary Policy During a Transition to Rational Expectations," Journal of Political Economy (Oc-

tober 1975), pp. 1009-21; and by Benjamin M. Friedman,

"Optimal Expectations and the Extreme Information Assumptions of "Rational Expectations" Macromodels," Journal of Monetary Economics (January 1979), pp. 23-41. 
inflation (and hence the benefits of reducing inflation) are not as clear cut or easily quantifiable as the costs of unemployment. Currently, no studies provide estimates of the benefits that would accrue from reducing or eliminating inflation, which could in turn be compared directly to the cumulative output loss required to eradicate inflation. What can be computed, however, is the minimum size of the permanent gain in output per year due to the eradication of inflation that would justify incurring the cumulative output loss associated with the transition to price stability.

\section{The Costs of Inflation}

There are at least three dimensions to the costs of inflation. ${ }^{24}$ First, there are the costs associated with anticipated inflation that would be incurred even in a fully indexed economy where institutions have completely adapted to an inflationary environment. Second, there are the costs of anticipated inflation that arise from a set of institutions that have only partially adapted to the inflationary environment. Third, there are the costs associated with unanticipated inflation and uncertainty about the rate of inflation.

A fully indexed economy is one in which all nominal payments and receipts (including wages, coupon payments, taxes, transfers, etc.) are tied (indexed) to the inflation rate. All debt instruments except for currency are indexed also. Currency is not indexed because indexing it is assumed to be impractical.

The major costs of anticipated inflation in a fully indexed economy can be labeled "menu" and "shoe leather" costs. Menu costs refer to the resource costs imposed by the necessity of frequent adjustments to published price lists in an inflationary economy. Shoe leather costs describe the costs incurred by more frequent trips to the bank (or to the market) as a result of the incentive to economize on currency holdings. ${ }^{25}$

Recently there has been a growing emphasis on the costs imposed by inflation that reflect the existence of institutions that are not fully adapted to an inflationary environment. The major source of these costs is the tax system, and the major effect is on saving and investment incentives and, therefore, on capital accumulation and the growth of output. The taxation

\footnotetext{
24The discussion of the costs of inflation in this section draws upon the recent survey by Stanley Fischer and Franco Modigliani, "Towards an Understanding of the Real Effects and Costs of Intlation," Weltwitschaftliches Atchiv (4: 1978), pp. $810-33$.

25For a discussion of the welfare cost of anticipated inflation, see John A. Tatom, "The Welfare Cost of Inflation," this Review (November 1976), pp. 9-22,
}

of personal interest income, for example, may induce a decline in the after-tax real rate of return to savers as inflation increases. ${ }^{26}$ Furthermore, the tying of the depreciation deduction for tax purposes to the historical rather than the replacement cost of capital goods tends to raise the cost of using capital goods in an inflationary environment. While inflation has many other effects on saving and investment, there is grow ing concern that its net effect is to discourage both saving and investment.

Unanticipated inflation imposes costs by inducing redistributions of income and wealth. These "transfer effects" arise because contracts have been written in nominal terms embodying expectations about future inflation which turn out to be incorrect. The social cost of such redistributions is difficult to assess because there is a gainer for every loser. However, many consider the "transfer" costs associated with unanticipated inflation the most serious cost associated with inflation. ${ }^{27}$

Uncertainty about the inflation rate may impose additional costs by increasing the uncertainty associated with the outcome of economic decisions. Above, a cost was ascribed to the actual redistributions that follow from unanticipated inflation. There may also be utility losses associated with the increased likelihood of such arbitrary transfers when there is considerable uncertainty about expected inflation. A number of studies have suggested that inflation uncertainty tends to be systematically related to the level of inflation. If this is the case, reducing the level of inflation will also reduce inflation uncertainty. ${ }^{28}$

Fischer and Modigliani do not provide estimates for the various effects of inflation since "any measures

26 For a discussion of the effect of taxation of interest income on the response of nominal interest rates to a change in expected inflation, see Martin Feldstein, "Inflation, Income Taxes, and the Rate of Interest: A Theoretical Analysis," American Economic Review (December 1976), pp. 809-20.

27Franco Modigliani and Lucas Papademos, "Optimal Demand Policies Against Stagflation," Weltwittschaftliches Archiv (4: 1978), pp. 736-82.

285ee, for example, Arthur M. Okun, "The Mirage of Steady Inflation,"Brookings Papers on Economic Activity (2:1971), pp. 485-98; and Dennis E. Logue and Thomas D. Willett, "A Note on the Relation Between the Rate and Variability of Inflation," Economica (May 1976), pp. 151-58. These studies generally associate an increase in inflation uncertainty directly with an increase in the welfare cost of inflation. This follows only if increased uncertainty about inflation inereases uncertainty about real income, real wealth, etc. For a discussion of the relation of inflation uncertainty to the welfare cost of inflation, see Lionel Kalish III, Laurence $H$. Meyer, and David H. Resler, "Inflation Uncertainty and the Welfare Cost of Inflation," mimeographed (Federal Reserve Bank of St. Louis, 1980). 


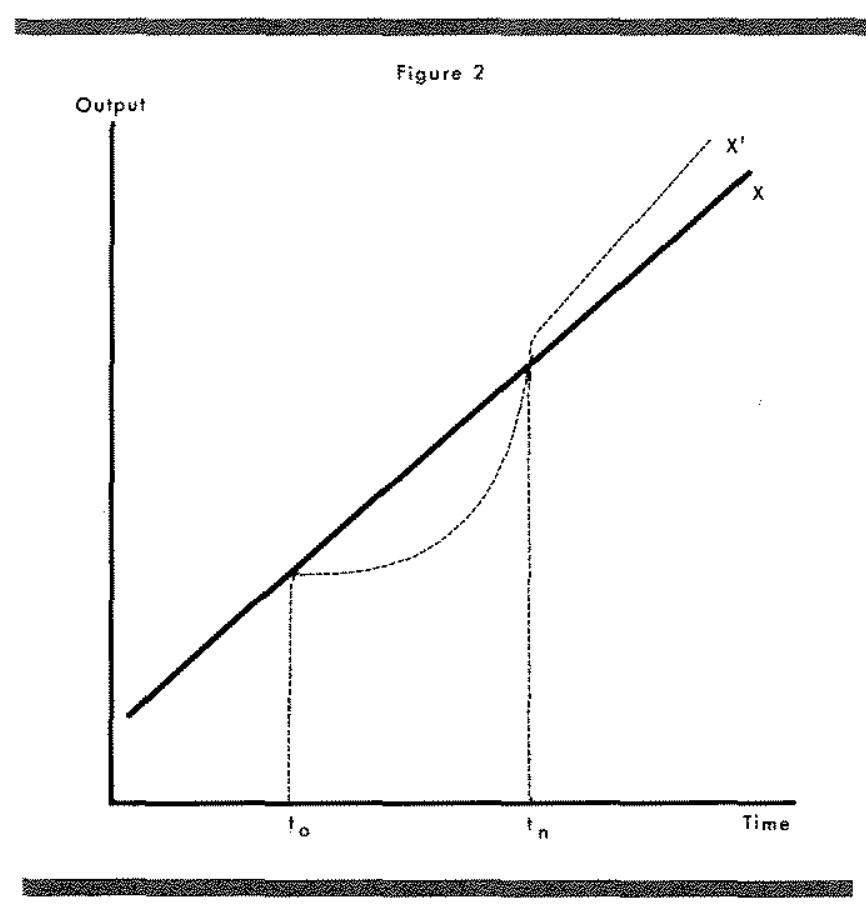

would be totally speculative at this stage." In the absence of a measure of these costs, however, it is possible to compute the minimum total costs associated with continued inflation necessary to justify incurring the previously calculated costs of eradicating inflation. ${ }^{30}$

\section{Evaluating the Minimum Gain Per Year Required to Mustify Policies to Eradicate Inflation}

The solid line $(X)$ in figure 2 is the rate of growth of potential output if inflation remains indefinitely at 7.5 percent. If anti-inflation policies are pursued, output is assumed to follow the dashed line $\left(X^{\prime}\right)$. The transitional costs of eradicating inflation occur between $t_{0}$ and $t_{n}$ as unemployment rises above the rate associated with potential output.

The cost of inflation may involve decreases in potential output due to disincentives to saving and/or investment and/or welfare losses due to anticipated or unanticipated inflation. The benefit of eradicating inflation is shown in figure 2 as an increase in output above the level that would have prevailed had infla tion continued to average 7.5 percent; hence, the ${ }^{29}$ Fischer and Modigliani, "Towards an Understanding of the
Real Effects and Costs of Inflation," p. 813 .

30This approach was suggested to $\mathrm{us}$ by Jerry Jordan and Allan Meltzer.

\section{Table 1}

The Minimum Value of the Per Year Gain (g) That Justifies Eradicating Inflation (billions of 1972 dollars)

\begin{tabular}{|c|c|}
\hline $\begin{array}{l}\text { Equation/ } \\
\text { model }\end{array}$ & Value of $\mathrm{g}$ \\
\hline Perry 1 & $\$ 73.0$ \\
\hline Perry 2 & 70.9 \\
\hline Steln 1 & 310 \\
\hline stein 2 & 25.4 \\
\hline
\end{tabular}

dashed $\mathrm{X}^{\prime}$ line rises above the solid $\mathrm{X}$ line after $\mathrm{t}_{\mathrm{n}}{ }^{31}$ This analysis emphasizes the necessity of comparing the transitional cost incurred over the period during which inflation is eradicated with the permanent benefit attributable to the eradication of inflation.

$\mathrm{G}$ is the present value of the permanent per period output gain, evaluated from period $\mathrm{n}$ to $\infty$ :

(11) $\mathrm{G}=\sum_{\mathrm{t}=\mathrm{n}}^{\infty} \frac{\mathrm{g}_{\mathrm{t}}}{(1+\mathrm{r})^{\mathrm{t}}}$.

To simplify further, $\mathrm{g}_{\mathrm{t}}$ is assumed to be constant for all $\mathrm{t} \geq \mathrm{n}$. The value of $\mathrm{g}$, which equates the discounted cost of unemployment and the gain from eradicating inflation is then calculated. This is the minimum value of the permanent per period gain from eradicating inflation that would justify incurring the transitional costs. The values of $\mathrm{g}$, based on transitional costs estimated from the Perry equation and Stein model and calculated under the assumption of a 3.3 percent discount rate, are presented in table 1 . The minimum value of $g$ varies from about $\$ 25$ billion per year in the Stein model to $\$ 73$ billion based on Perry's Phillips Curve under a moderate policy.

This analysis provides an alternative perspective on the case for gradualism. A gradual policy will impose a lower cost of eradicating inflation if the Phillips Curve is nonlinear. For Perry's nonlinear Phillips Curve, for example, the discounted cost was $\$ 1.0$ billion for the gradual policy and $\$ 1.5$ billion for the

31The gains of reducing inflation should begin being registered during the transition period. To simplify the calculation, the benefits are assumed to begin only at $t_{n}$, when inflation is eradicated. This assumption biases the calculation of the present value of benefits downward. 
more aggressive policy. A more gradual policy, how ever, also postpones the benefits from eliminating inflation. The size of the permanent per period gain required to justify the anti-inflation policy mav therefore be smaller under the more aggressive policy. Indeed, this is the case for the Perry results. Although the cumulative output loss is smaller under the grad ual policy (Perry 1), the size of the per period gain required to justify eradicating inflation is smaller under the more aggressive policy (Perry 2). The more aggressive policy also yields a smaller minimum per period gain using the Stein model, although this was expected since the cost turned out to be lower in the radical case using Stein's model.

The calculations reported above presumed that the gains from reducing inflation could be meaningfully represented as a fixed real sum per period. Suppose, instead, that the gains are more meaningfully specified as a real sum which grows at the same rate as potential output. For example, the cost of a fully anticipated increase in inflation is generally measured by the reduction in the area under the demand curve for real money balances as wealthowners reduce their demand for money in response to the associated rise in nominal interest rates. The decline in demand for real money due to a rise in the interest rate is generally considered proportional to the overall scale of money holdings which, in turn, is determined by the level of transactions (e.g., real income). The cost of a given rate of inflation and, hence, the benefits of eliminating inflation may, therefore, grow at the rate of increase of potential output. In this case:
(11') $G=\sum_{\mathrm{t}}^{\infty} \frac{\mathrm{g}(1+\rho)^{\mathrm{t}}}{(1+\mathrm{r})^{\mathrm{t}}}$,

where $g$ is the value of the gain in period $n$ (the first period in which a gain is registered). For $\rho>r, G$ $\rightarrow \infty$. This corresponds to the result recently derived by Feldstein: If the cost of inflation grows at a rate equal to or greater than the discount rate, any positive initial gain (any $g>0$ ) is sufficient to justify incurring any finite transitional cost! ${ }^{32}$

\section{CONCLUSION}

The existence of large transitional costs of eradicating inflation is not a sufficient reason to reject antiinflation policies. The potential existence of large benefits associated with reducing inflation requires a careful assessment of the net effects of anti-inflation policies. Unfortunately, the range of the estimates of the cumulative output loss, the uncertainty about the adjustment in those results required to allow for the credibility effect, and the lack of quantitative estimates of the cost of inflation make it extremely diffcult to obtain a meaningful comparison of the costs and benefits of an anti-inflation policy. Narrowing the range of estimates of output loss and developing a measure of the benefits associated with anti-inflation policies should be high on the priorities for macroeconomic research in the 1980 s.

"Martin $\mathrm{S}$. Feldstein, "The Welfare Cost of Permanent Inflation and Optimal Short-Run Economic Policy," Journal of Political Economy (August 1979), pp. 749-67.

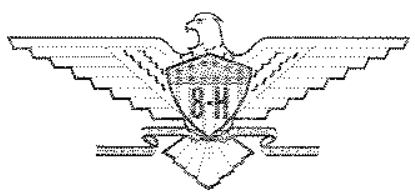

